\title{
Long-range effects of castration on mating behavior in the male rat*
}

\author{
ARIEL MERARI, VARDA SHOHAM \\ GERSHON MOLAD, and HAIM PERRI \\ Tel-Aviv University, Ramat-Aviv, Tel-Aviv, Israel
}

The copulatory behavior of 14 male rats was measured following castration. Mating tests continued until the complete disappearance of ejaculations, intromissions, mounts, and incomplete mounts. The results showed that, whereas the ejaculation pattern responses disappeared within 8 weeks from castration, the last intromission was observed in the 18 th week, and both complete and incomplete mounts were still performed by one male in the 28 th postoperative week. These findings are interpreted as indicating that the motivation to copulate outlasts the sensory and motor components of copulatory behavior after castration.

The general course of castration effects on mating behavior in the male rat has been known for a long time (e.g., Stone, 1939; Beach \& Holz-Tucker, 1949; Davidson, 1966a). It has been shown that the loss of copulatory behavior following castration is gradual, starting with the disappearance of ejaculations, ${ }^{1}$ then intromissions, and finally mounting responses.

Mating behavior, however, is a complex phenomenon, involving motivational, sensory, and motor mechanisms. The loss of capability to perform different copulatory activities may result from a motivational deficit (i.e., lack of interest in the estrous female), sensory damage (such as reduced afferent information from the penis due to degenerative changes), specific motor impairment, or a combination of these. So far, experimenal analysis of the effects of castration have not differentiated between these possible sources of behavioral decline.

While a clear experimental distinction between motivation, sensory, and motor effects is quite difficult to obtain, it is nevertheless possible to indicate the presence or absence of motivation to copulate, even in a male who does not show full mating behavior by referring to attempted mounts. It is assumed here that as long as the male is motivated to mate, he continues to try to do so, although such attempts may be unsuccessful due to reduced sensory feedback or impaired motor ability. Thus, in a mating test, attempted mounts should be regarded as the most sensitive measure of copulatory motivation.

The purpose of the present study was to investigate the changes in mating behavior of male rats following castration, until the complete disappearance of sexual motivation.

\section{METHOD}

Subjects

Fourteen sexually experienced, albino male rats of the

\footnotetext{
*Sponsored by Donald A. Dewsbury, who takes full editorial
} responsibility for it.
Weizman B-1 strain, weighing $335-480 \mathrm{~g}$ at the start of the experiment, were used as Ss. Prior to the beginning of testing, all of the Ss served as stud males. They were housed four in a cage and were kept on a reversed daylight cycle, the lighted portion of which began at 7 p.m. and ended at 7 a.m. Mating tests were always performed in the dark part of the cycle.

The ovariectomized stimulus females were artificially brought into estrus by means of intramuscularly injecting $0.1 \mathrm{mg}$ of estradiol benzoate $248-72 \mathrm{~h}$ and $0.4 \mathrm{mg}$ of progesterone $3-4 \mathrm{~h}$ before the mating tests. Estrus was examined by placing the females with a vigorous nonexperimental male. Only females that proved to be highly estrous were used in the mating test.

\section{Mating Tests}

These tests were conducted in a $67 \times 31 \times 37 \mathrm{~cm}$ plywood box with a transparent front. The males were tested one at a time. Each male was given a 5-min adaptation period in the box before the female was introduced. The timing and frequency of mounts, intromissions, and ejaculations, as well as incomplete (attempted) mounts, were recorded on a Rustrak event recorder. An incomplete mount was recorded whenever the male placed his forepaws on the female's back or clasped her without pelvic thrusts. The test was carried through the first intromission after ejaculation. In cases where ejaculation was not achieved within $30 \mathrm{~min}$ after the first intromission, the test was stopped at that time. However, the test was terminated $30 \mathrm{~min}$ after its start when no intromission occurred by that time.

\section{Procedure}

In order to verify his sexual potency, each one of the males was observed to perform an ejaculation prior to castration. Upon completion of these preliminary mating tests, each of the 14 males was subjected to trans-scrotal castration under ether anesthesia. The first postcastration mating test was performed a month after the operation, and another month elapsed before the second mating test. From that time on, the intertest interval was kept at 2 weeks, until the criterion for loss of mating behavior was reached. This criterion was determined to be three consecutive mating tests without any complete or incomplete mounts. One of the males, however, did not fully meet this criterion at the end of the experiment. His last mating test took place 30 weeks after castration, in spite of the fact that this $S$ had still shown mounting behavior in the previous test.

\section{RESULTS AND DISCUSSION}

The decline of ejaculations, intromissions, mounts, and incomplete mounts is shown in Table 1. It is apparent that the rate of loss of ejaculation and intromission responses was considerably faster than the disappearance of mounts and incomplete mounts. While no ejaculation responses were observed since the 8 th week, and the last intromission was recorded in the $18 \mathrm{th}$ post-castration week, mounts and incomplete mounts were still performed by one male in the 28 th week.

It is also evident that there was a large degree of correspondence between the execution of intromissions and the occurrence of ejaculation responses. With a very few exceptions, once a male succeeded in achieving an intromission, he continued copulation until ejaculation was reached within the predetermined time limits of the test.

With all types of responses considered, mating 
Table 1

Frequencies of Various Copulatory Responses on Successive Tests After Castration

\begin{tabular}{|c|c|c|c|c|c|c|c|c|}
\hline \multirow[b]{3}{*}{$\begin{array}{l}\text { Weeks After } \\
\text { Castration }\end{array}$} & \multicolumn{6}{|c|}{ Response } & & \\
\hline & \multicolumn{2}{|c|}{ Incomplete Mounts } & \multicolumn{2}{|c|}{ Mounts } & \multicolumn{2}{|c|}{ Intromissions } & \multicolumn{2}{|c|}{ ljaculation, } \\
\hline & $\mathrm{N}^{*}$ & $\begin{array}{c}\text { Mean } \\
\text { Frequency }\end{array}$ & $\mathrm{N}$ & $\begin{array}{c}\text { Mean } \\
\text { Frequency }\end{array}$ & $x$ & $\begin{array}{c}\text { Mean } \\
\text { Irequency }\end{array}$ & $\therefore$ & $\begin{array}{c}\text { Mean } \\
\text { Irequent }\end{array}$ \\
\hline 4 & 14 & 9.64 & 11 & 9.63 & 7 & 5.00 & 6 & 1.1111 \\
\hline 8 & 8 & 4.75 & 2 & 9.00 & 1 & 3.00 & 11 & 11 \\
\hline 10 & 7 & 10.42 & 4 & 1.25 & 1 & 2.00 & 0 & 1) \\
\hline 12 & 6 & 4.16 & 0 & 0.00 & 0 & 0.00 & 0 & 11 \\
\hline 14 & 3 & 5.66 & 3 & 1.33 & 0 & 0.00 & () & n \\
\hline 16 & 3 & 5.66 & 1 & 3.00 & 0 & 0.00 & 0 & 11 \\
\hline 18 & 2 & 7.00 & 2 & 5.00 & 1 & 4.00 & 1) & 11 \\
\hline 20 & 4 & 4.00 & 0 & 0.00 & 0 & 0.00 & () & 11 \\
\hline 22 & 1 & 7.00 & 1 & 1.00 & 0 & 0.00 & () & () \\
\hline 24 & 3 & 2.00 & 0 & 0.00 & 0 & 0.00 & () & 0 \\
\hline 26 & 1 & 4.00 & 0 & 0.00 & 0 & 0.00 & () & () \\
\hline 28 & 1 & 3.00 & 1 & 2.00 & 0 & 0.00 & () & () \\
\hline 30 & 0 & 0.00 & 0 & 0.00 & 0 & 0.00 & 0 & 11 \\
\hline
\end{tabular}

*I is the number of rats that showed the response during the test.

behavior did not disappear abruptly. but rather became more and more scarce, until it was finally abolished.

Having accepted that the occurrence of incomplete mounts indicated the existence of motivation to mate, one may interpret these results as demonstrating that, following castration. the motivation to copulate declines more slowly than the ability to perform successfully copulatory activities. In other words, the male is still willing to copulate and attempts to do so in spite of the fact that he is already unable to achieve ejaculation. intromissions, or even properly executed mounts. The cause of this failure is either motor or sensory deficit. or both. Support for this logical interpretation may be found in a different experimental situation. In studies where the sensory feedback from the rat's penis was reduced by application of a local anesthetic (Adler \& Bermant, 1966) or by severing the sensory innervation of the cat's penis (Aronson \& Cooper, 1966), the experimental males executed a large number of mounts, but were able to achieve only a few intromissions, or none at all. In a different line of investigation, Beach \& Westbrook (1967) injected castrated male rats with the synthetic androgen fluoxymesterone, which had been claimed to have peripheral but not central androgenic effects. This drug failed to restore mating behavior in five males which had completely stopped copulation prior to its administration, -although the treated rats showed marked penile and accessory glands recovery from the effects of castration. Another two males, however, had still shown some mounts at the onset of fluoxymesterone administration. These Ss showed considerable restitution of mating behavior. including ejaculatory responses. following the drug treatment. These results support the notion that as long as there exists sexual motivation after castration. it is possible to revive the full complement of mating behavior by restimulating the peripheral (probably mainly sensory) system alone. Furthermore, the results of the present investigation suggest that following castration the copulatory motivation outlives the sensory or motor functions. so that the male is no longer capable of executing ejaculation or intromission responses at the time when he is still willing to mate. More caution is therefore needed in studies that involve manipulations of mating behavior after castration. Such studies often use the criterion of failure to perform intromissions or ejaculations as a proof of a lost motivation to copulate (e.g. Davidson, 1966b), while a more sensitive measure of copulatory motivation. preferably incomplete mounts, is necessary.

\section{REFERENCES}

Adler, N., \& Bermant, G. Sexual behavior of male rats: Effects of reduced sensory feedback. Journal of Comparative \& Physiological Psychology, 1966, 61, 240-243.

Aronson, L. R., \& Cooper, M. L. Seasonal variation in mating behavior in cats after desensitization of glans penis. Science. $1966,152,226-230$.

Beach, F. A., \& Holz-Tucker, A. M. Effects of different concentrations of androgen upon sexual behavior in castrated male rats. Journal of Comparative \& Physiological Psychology. $1949,42,433-453$.

Beach, F. A., \& Westbrook, W. H. Dissociation of androgenic effects on sexual morphology and behavior in male rats. Endocrinology, 1968, 83, 395-398.

Davidson, J. M. Characteristics of sex behavior in male rats following castration. Animal Behaviour, 1966a, 14, 266-272.

Davidson, J. M. Activation of the male rat's sexual behavior by intracerebral implantation of androgen. Endocrinology. $1966 \mathrm{~b}, 79,783-794$.

Stone, C. P. Copulatory activity in adult male rats following castration and injections of testosterone propionate. Endocrinology, 1939, 24, 165-174.

\section{NOTE}

1. When used in relation to castrated males, the term "ejaculation" means the behavioral pattern of ejaculation.

2. Estradiol benzoate used was "Assia" Ltd. "Di-oestrogyn," $5 \mathrm{mg} / \mathrm{cc}$. The progesterone was "Assia" Ltd. "Progestin." $25 \mathrm{mg} / \mathrm{cc}$. The authors are grateful to "Assia" Ltd. for donating these hormones.

(Received for publication June 29. 1973.) 